\title{
Legislative Bargaining with Teams
}

\author{
Anthony J. Bradfield ${ }^{\mathrm{a}, \mathrm{b}}$
}

John H. Kagel ${ }^{\mathrm{a}, \mathrm{c}}$

August 7, 2015

\begin{abstract}
We study legislative bargaining with two person teams versus individuals. Teams come closer to the predictions of the stationary subgame perfect equilibrium, passing minimum winning coalitions (MWCs) more often and having significantly more proposer power. The increase in proposer power results from increased numbers of MWCs, along with increased proposer power within an MWC. We investigate the driving forces behind teams coming closer to the theoretical predictions. The results favor their greater insightfulness as opposed to being more aggressive or more selfish.
\end{abstract}

Key words: Legislative bargaining, teams versus individuals, truth wins JEL codes: D73, D03, D02

a Department of Economics, The Ohio State University, 410 Arps Hall, 1945 N. High St., Columbus, $\mathrm{OH} 43210$, United States

${ }^{\mathrm{b}}$ E-mail address: bradfield.16@osu.edu

${ }^{\mathrm{c}}$ Corresponding author, E-mail address: kagel.4@osu.edu 
We experimentally investigate the Baron-Ferejohn (BF, 1989) legislative bargaining model, comparing the behavior of two person teams to individuals. The Baron-Ferejohn model is the leading formal model of the legislative bargaining process. It has been explored experimentally under a variety of specifications, including variations in the size of the committee, voting rules ranging from majority rule to a veto player, whether proposals can be amended, and different costs of delay in reaching agreements, to name a few (see Palfrey, 2015, for a review). To date, all of these experiments have employed individual decision makers as bargainers. However in practice, committee bargaining is usually done in teams made up of a support staff and/or coalition partners. As such it is important to identify any major differences between team and individual behavior in the bargaining process.

Past research on team versus individual behavior shows that teams typically come closer than individuals to the predictions of standard economic theory in a wide variety of settings (see Charness and Sutter, 2012, and Kugler, Kausel, and Kocher, 2012, for surveys). For example in the closely related ultimatum bargaining game, Bornstein and Yaniv (1998) show that teams offer significantly less to responders than individuals, with teams willing to accept lower offers as well, thereby coming closer to the subgame perfect equilibrium (SPE) prediction. Likewise, Casari, Jackson, and Zhang (2012) show that in the takeover game (Bazerman and Samuelson, 1983), teams suffer less often from the winner's curse and generally earn more money than individuals.

The BF legislative bargaining game has multiple Nash equilibria as well as multiple SPE. The stationary subgame perfect equilibrium (SSPE) is the standard reference point, generating unique equilibrium predictions. It is essentially the SPE with history independent strategies (no punishment strategies across stages of the game). The SSPE has three main predictions: (i) proposals are accepted without delay, (ii) proposals involve minimum winning coalitions (MWCs) that give nothing to redundant voters, and (iii) there is strong proposer power (e.g. in our game, with three players, majority rule, and $\$ 30$ at stake, the proposer takes $\$ 20$ and gives $\$ 10$ to her coalition partner).

Past research with individual subjects as players is qualitatively consistent with the model's predictions as: (i) the majority of bargaining rounds end with the first proposal, (ii) a large number of MWCs are present to begin with, and the number increases over time, and (iii) 
on average proposers earn more than other players. ${ }^{1}$ However, a sizable number of bargaining rounds end with shares to all players, with shares close to the SSPE prediction rarely offered or accepted. Given these results, and the common finding that teams come closer to the game theoretic predictions than individuals (which we will refer to in short as "rational" play), one would expect closer adherence to the SSPE with teams. In particular one would expect a higher frequency of MWCs along with increased proposer power. If indeed teams come closer to these equilibrium predictions, one can imagine several possible driving forces: teams, having two heads to work with, may be more insightful and have a better understanding of the underlying strategic tradeoffs. Alternatively, teams may come closer, because they are inherently more aggressive or selfish as much of the psychology and economics literatures assume. ${ }^{2}$ These alternative driving forces are discussed below within the context of the BF game.

If teams are more insightful, one would expect them to more readily recognize that proposals should involve MWCs, as under majority rule redundant players' votes do not matter. And should one member of the team understand this, it should be easy enough to explain this insight to their partner so that the team proposes an MWC. The latter in turn might be expected to increase the proposer's share (proposer power) due to both the carrot and the stick: proposers have more money available to split with their coalition partners (the carrot), and rejecting a decent share opens up the possibility of a zero share when the new proposer is chosen (the stick). ${ }^{3}$ Of course if teams are inherently more aggressive, this would be expected to produce the same result, as they strive for more money. However, as Borenstein and Yaniv (1998) note for the ultimatum game, more aggressive teams as responders/voters would be expected to reject

\footnotetext{
${ }^{1}$ These qualitative results hold even in the face of some history dependent strategies following rejected proposals.

${ }^{2}$ Much of the psychology literature on groups being more aggressive, or less other regarding (selfish), than individuals rests on the "discontinuity effect" showing that teams are less cooperative than individuals in repeated prisoner's dilemma games (Insko and Schopler, 1987, and Schopler and Insko, 1992). However, see Halevy, Bornstein, and Sagiv (2008) and Kagel and McGee (2015) for a different perspective on the discontinuity effect. Charness and Sutter (2012) emphasize the greater insightfulness of teams as underlying their closer to equilibrium outcomes but note that additional contributing factors include groups being more likely to emphasize monetary payoffs over concerns for fairness and reciprocity.

${ }^{3}$ The carrot part holds within the context of risk neutral agents. The stick applies to risk averse agents (Harrington, 1990). Note, we would not expect teams to propose and pass SSPE shares as that is substantially harder to figure out, no less explain to a teammate. A number of alternative explanations have been proposed to rationalize the common failure to achieve the predicted level of proposer power: Fréchette (2009) shows that a learning model in which subjects start out choosing the "obvious" equal division is, with learning, (incompletely) replaced by strategic considerations within an MWC. Nunari and Zapal (2014) show how a model incorporating a combination of imperfect best response (a QRE model) in conjunction with incorrect beliefs regarding future proposer power (the gambler's fallacy) does the trick.
} 
comparable offers more often, at least early on. ${ }^{4}$ As for teams being more selfish, this would likely reflect minimal concern for third parties (in the BF games, redundant voters) along with, possibly, asking for larger shares.

To summarize our results in the context of these factors, we find teams forming MWCs substantially more often than individuals to the point of meeting, and at times beating, the demanding "truth wins" norm (Lorge and Solomon, 1955, and Davis, 1992). Proposers earn significantly larger shares within teams, partly as a consequence of the increased frequency of MWCs and partly as a function of asking for and obtaining larger shares in approved allocations. This occurs within a context of stage one proposals being equally likely to pass in both cases and with regressions showing that teams are as likely, if not more likely, than individuals to accept comparable shares, both of which are inconsistent with teams being more aggressive. With respect to teams being more selfish, we appeal to results from a closely related three player ultimatum game (Kagel and Wolfe, 2001) and a recent BF experiment (Baranski and Kagel, 2015) showing that individuals have essentially zero concern for third parties, leaving no room for teams to be even less concerned. Finally, we do find that teams are more aggressive in that they are more likely to punish proposers after a proposal is rejected. However, this does not conflict with their (rationally) voting in favor of proposals with payoffs close to the continuation value of the game more often than individuals do.

Much of the present paper is concerned with insights gained from communication between team members (within team communication) that is needed to coordinate their choices and to gain the benefit of each other's insight. Two recent papers have also focused on communication in the BF game (Agranov and Tergiman, 2014, and Baranski and Kagel, 2015). The key distinction between these two studies and the present one is that the former involve individual agents engaged in cheap talk prior to making proposals, as they jockey to be included in the winning coalition. Both papers report increased numbers of MWCs (compared to no communication) and proposer power substantially closer to the SSPE than anything reported to date (including the present paper). However, this does not detract from the present exercise as (i) bargaining outside the lab usually takes place within teams, so these differences are of inherent

\footnotetext{
${ }^{4}$ We say at least early on as higher rejection rates might be expected to feed back into higher offers over time, which does not happen.
} 
interest, and (ii) we can sort out, at least in this case, between competing explanations for why teams come closer to equilibrium outcomes. ${ }^{5}$

The remainder of the paper is structured as follows: sections 1 and 2 summarize the experimental design and the predictions of the BF model for our design. Section 3 reports the experimental results, with section 4 reporting results from the analysis of the team chats. Section 5 concludes with a brief summary and discussion of the main results.

\section{Experimental Design}

The Baron-Ferejohn (BF, 1989) legislative bargaining game has five major components: the number of bargainers, the proposal recognition rule, the proposal amendment rule, the voting rule for determining whether a proposal passes, and the cost of delay in passing a proposal. In the present experiment each bargaining group consists of three players (three two-person teams or three individuals) deciding how to split $\$ 30$. In what follows we will refer to the two-person teams and individuals as players, except when making a distinction between the two. In each bargaining round, each player proposes an allocation of the $\$ 30$, with it being common knowledge that one the proposals will be randomly (and uniformly) selected to be voted on. The player whose proposal is selected is referred to as the proposer, with the other two players referred to as voters. Proposals are voted up or down with no opportunity for amendment. If a simple majority votes in favor of the proposal, it passes. Otherwise, the process repeats itself, with no cost of delay (no discounting), until a proposal passes, so there may be multiple stages (proposals and votes) within a given bargaining round.

Once a proposal passes, players are randomly reassigned to new three player bargaining groups, for a total of ten bargaining rounds in each experimental session, along with an initial dry run where players are walked through the software. Bargaining groups that finish early see a "please wait" screen until all groups have successfully passed a proposal. Payments were based on the distribution of the $\$ 30$ in one randomly selected bargaining round, plus an $\$ 8$ participation fee. Each subject in a two-person team received the money allocated to their team. ${ }^{6}$ Sessions lasted approximately one hour and 15 minutes.

\footnotetext{
${ }^{5}$ There is room for cheap talk between teams to compare to these other two papers. But that goes well beyond the scope of the present paper.

${ }^{6}$ Payoffs were not split between teammates. This keeps incentives and framing constant between the two treatments.
} 
In the individual subject sessions, each player had one minute to make their proposals and another minute to vote. This restriction was rarely binding, with any players failing to make a decision in that time prompted to do so by the experimenter. ${ }^{7}$ Teams had three minutes to agree on a proposal, and another three minutes to determine how to vote. They had a chat box that was continuously open to coordinate their choices. Each team's decision was locked in after five seconds following both subjects submitting the same decision. There were defined rules for what would happen if no joint decision had been made, but this rarely happened. ${ }^{8}$ Team composition remained the same for an entire experimental session.

Subjects were undergraduate students at The Ohio State University who were enrolled in the Economics Department subject pool and who had not participated in any previous BF bargaining experiment. ${ }^{9}$ There were three team sessions and three individual sessions with between 3 and 5 bargaining groups in each session. ${ }^{10}$ The experiment was programmed with zTree (Fischbacher, 2007).

\section{Theoretical Predictions}

The BF model has multiple Nash equilibria, with any accepted proposal constituting a Nash equilibrium, as well as a number of subgame perfect equilibria (SPE). ${ }^{11}$ The stationary subgame perfect equilibrium (SSPE) offers a unique prediction (with the exception of which voter is included in the MWC). The SSPE is essentially an SPE for the game when players do not exercise any history based punishment strategies across stages. Under the SSPE, proposals always pass without delay with proposers forming MWCs. Potential coalition partners receive a share equal to the continuation value of the game - their expected payoff after rejecting an offer. Under standard assumptions of perfectly rational, risk neutral players and no discounting, this is equal to $\$ 10$, with the proposer keeping $\$ 20$. Predictions of the model are unaffected by whether players are teams or individuals.

\footnotetext{
${ }^{7}$ These players were typically "asleep at the wheel." In any case, we had no complaints about the decision period being too short as we queried subjects on leaving the first experimental session.

${ }^{8}$ See http://econ.ohio-state.edu/kagel/Insts_teams_BF_3_player_AB.pdf for the instructions which enumerate these rules. A team ran out of time only four times in the proposal stage and never ran out of time when voting. If a team could not coordinate their decisions in time, one of their proposals was randomly selected.

${ }^{9}$ One subject in the teams treatment had participated in another legislative bargaining experiment. Another subject was the fiancée of a subject who had participated in an earlier legislative bargaining experiment, with the team dialogues indicating the two had discussed some elements of the experiment.

${ }^{10}$ There were 9 teams in one session and 12 in the other two; there were 9 individuals in one of the individual subject sessions, 15 in the other two, for a total of 105 subjects.

${ }^{11}$ Herings, Meshalkin, and Predtetchinski (2013) report the set of subgame perfect equilibria for the case of $\mathrm{n}=3$.
} 
As noted in the introduction, previous experiments with individual subjects bargaining under similar designs have found qualitative support for these predictions but have outcomes that are far from the point predictions of the SSPE. For example, Fréchette, Kagel, and Morelli (2005) report that in a three player game with inexperienced subjects, $65 \%$ of all proposals pass in Stage 1 over all 10 bargaining rounds, MWCs account for about two-thirds of passed proposals, and there is modest proposer power. ${ }^{12}$

\section{Experimental Results}

\subsection{Proposals}

In analyzing the experimental results, the emphasis will be on outcomes in the last five bargaining rounds, at which point players are much more familiar with the software and procedures. For payoffs, we refer to the voter receiving the larger share as the included voter and the voter receiving the smaller share as the excluded voter. ${ }^{13}$ Typically there are only minor differences between all proposals versus passed proposals, so unless otherwise noted, the analysis deals with passed proposals.

The SSPE predicts $100 \%$ MWCs. Teams come quite close to this in the last five bargaining rounds, averaging $96.1 \%$ of all proposals and $92.7 \%$ of passed proposals. ${ }^{14}$ This is in sharp contrast to individuals where $65.0 \%$ of all proposals were MWCs and $55.4 \%$ of passed proposals. Figure 1 compares teams with individuals round by round with respect to the truth wins (TW) prediction, along with the $90 \%$ confidence interval (CI) for TW. ${ }^{15}$ TW can be expected to hold for "eureka" type problems where the insight is reasonably straightforward, so that once it occurs to one subject, it is quite easy to understand and explain to others. TW implies that a team will play at the same or a higher level than its most able member acting alone (Lorge and Solomon, 1955). Satisfying TW would rarely be expected in most economic settings,

\footnotetext{
${ }^{12}$ With experienced subjects, there is some improvement toward the theoretical prediction for MWCs and passing proposals without delay. Other experiments with more bargainers show similar results (Palfrey, 2015).

${ }^{13}$ If both voters receive the same share, we count both as included, since they could each cast the pivotal vote.

${ }^{14}$ The definition of an MWC used here is when the excluded voter receives $\$ 1$ or less (typically $\$ 0$ ). The $\$ 1$ is a throw away payment which never secures their vote. There are only minor differences in results reported using a strict definition for an MWC (a \$0 payment).

${ }^{15}$ The TW calculations draw pairs of proposals, with replacement, from the individual subject sessions to form a "team" that proposes an MWC if one, or both, proposals are MWCs. We take the mean of the sample (with the number of "teams" in each sample equal to half the number of proposals in the individuals treatment) and repeat this process 100,000 times to determine the $90 \%$ confidence interval.
} 
as they rarely can be solved with a single eureka insight. ${ }^{16}$ However with respect to proposing MWCs, it's reasonably clear and easy to explain that proposers need only allocate adequate funds to enough committee members for a proposal to pass. ${ }^{17}$ Teams perform favorably against TW, falling within the $90 \%$ confidence interval for all bargaining rounds and the upper bound in each of the last 5 rounds. Aggregating over the last 5 rounds, teams beat TW, forming MWCs $96.1 \%$ of the time $(\mathrm{p}<0.001) .^{18}$

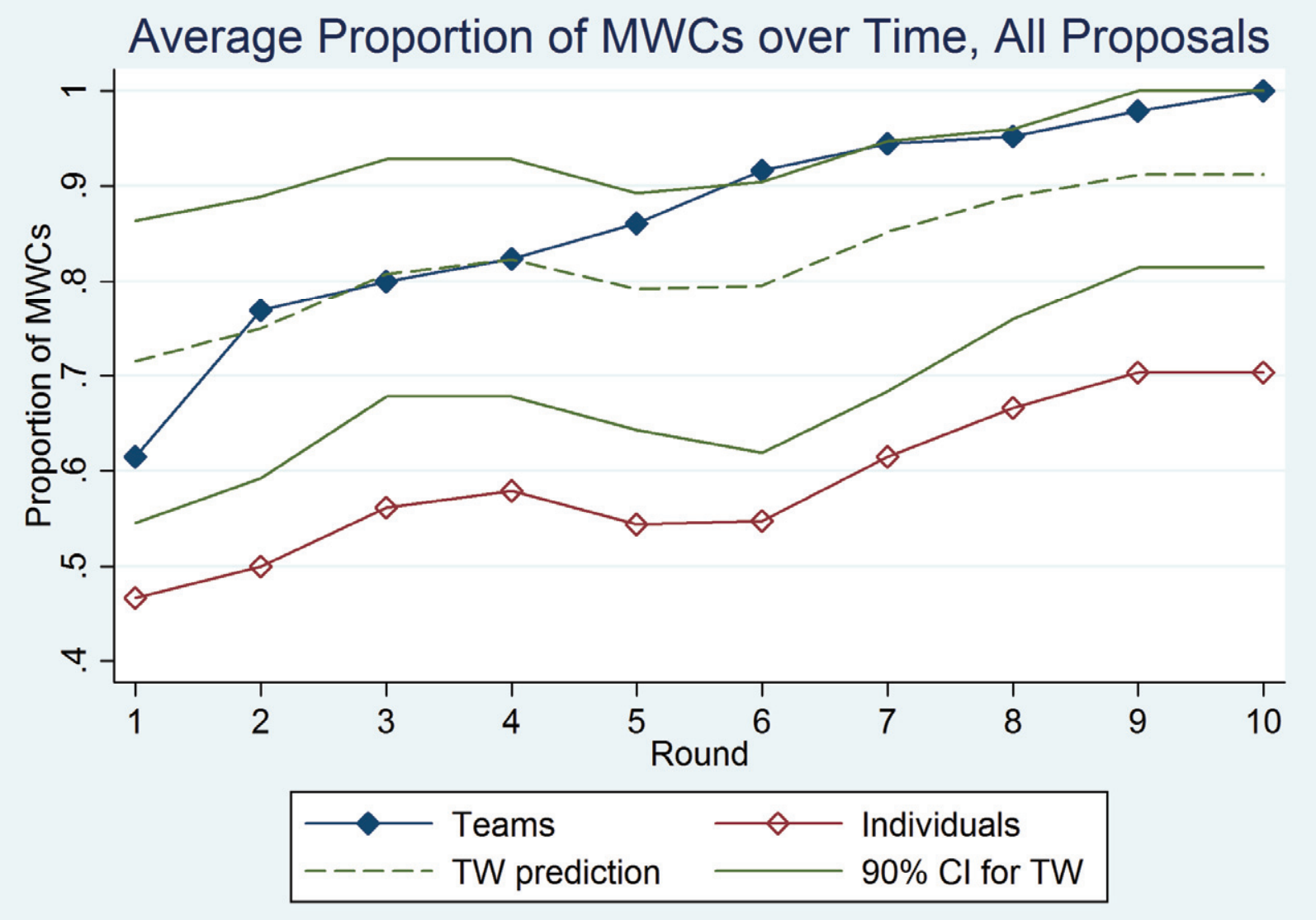

Figure 1: Proportion of MWCs and Bootstrapped Confidence Interval for Truth Wins

Result 1: Teams meet the truth wins norm with respect to MWCs for all bargaining rounds and are at the upper bound of the $90 \%$ confidence interval for rounds 6-10. Aggregating over the last

\footnotetext{
${ }^{16}$ For example, with respect to the winner's curse in the corporate takeover game, it's one thing to recognize that bidding less will lead to winning with a positive profit more often; it's another thing to fully understand the adverse selection effect conditional on winning and how to deal with it.

${ }^{17}$ This assumes no opportunity for amending proposals, which is typical in BF experiments.

${ }^{18}$ This is a bootstrapped p-value. Only 73 of 100,000 bootstrapped samples have over $96.1 \%$ MWCs according to truth wins, so $\mathrm{p}=0.00073<0.001$.
} 
5 bargaining rounds teams beat truth wins. ${ }^{19}$ The fact that teams meet or beat TW with respect to MWCs is supportive of the idea that they come closer to equilibrium predictions on account of the greater insightfulness that might be expected from teams in this setting.

Table 1 reports the percentage of proposals that follow the most common focal points the SSPE allocation, an equal split between only the proposer and the included voter (referred to as the MWC Equal Split), along with an equal split between all three players ( $\$ 10$ for each, referred to as the True Equal Split). In all cases, the percentages reported are either for the focal point exactly or within $\$ 1.00$ of the focal point. ${ }^{20}$ We use these weaker definitions as they better capture the frequencies for the focal points. For example, a split of $(\$ 11, \$ 9.50, \$ 9.50)$, where the proposer's share is listed first, is not materially different from a $\$ 10$ split all around and passes at essentially the same rate as under a strict definition.

\begin{tabular}{ccc} 
Focal Points & Teams & Individuals \\
\hline SSPE (20/10/0) & 9.1 & 0.0 \\
& $(4.0)$ & \\
MWC Equal Split & 40.0 & 49.2 \\
& $(6.5)$ & $(3.9)$ \\
Other MWC & 43.6 & 6.2 \\
& $(5.5)$ & $(3.9)$ \\
True Equal Split & 7.3 & 27.7 \\
& $(3.0)$ & $(4.4)$ \\
Other non-MWC & 0.0 & 16.9 \\
Observations & 55 & $(4.6)$ \\
\hline
\end{tabular}

Table 1: Focal Allocations as a Percentage of Passed Proposals, Last 5 Bargaining Rounds (standard error of the mean in parentheses) ${ }^{21}$

By far the most attractive focal allocation for both teams and individuals is the MWC Equal Split, accounting for $40 \%$ or more of passed proposals. There are no passed proposals approximating the SSPE for individuals (with none proposed as well), with a handful (9.1\%) passing for teams. The pass rate for these SSPE type proposals is a little less than $50 \%$. True Equal Splits are much more frequent for individuals, as well as proposals giving all three players

\footnotetext{
${ }^{19}$ Aggregating over all rounds, the result is moderately significant (bootstrapped $\mathrm{p}=0.053$ ).

${ }^{20} \mathrm{SSPE}$ is at least $\$ 19$ and $\$ 9$, with the excluded voter getting at most \$1. An MWC Equal Split is at least \$14 for the included voter and at most \$1 for the excluded voter. True Equal Splits consist of at least \$9 for all.

${ }^{21}$ The standard errors are the variation in the mean for each session and round in the last 5 rounds.
} 
more than a \$1 (Other non-MWC). Finally, the much higher frequency of Other MWC proposals for teams underlies the increased proposer power reported for teams.

Result 2: The most attractive focal point for proposals for both teams and individuals was an equal split between the proposer and the included voter within an MWC. However, teams are much more likely to pass MWCs with proposers taking a larger share than the included voter. ${ }^{22}$ Teams submit more SSPE type proposals, but these are rejected a bit more than $50 \%$ of the time.

Table 2 shows shares players received for passed proposals. Team proposers averaged $\$ 2.60$ more than individual proposers (nonparametric Mann Whitney rank sum test, $\mathrm{p}<0.01$ ). ${ }^{23}$ This represents a $19.1 \%$ increase in proposer power compared to individuals, along with a $13.0 \%$ increase in proposer power as a percentage of the SSPE prediction. At the same time, there is a very small increase of $\$ 0.18$ for the included voter which is not statistically significant.

\begin{tabular}{cccc} 
Shares of $\$ 30$ & Prediction & Teams & Individuals \\
\hline Share for Proposer $(\$)$ & $\$ 20$ & 16.21 & 13.61 \\
& & $(2.11)$ & $(2.37)$ \\
Share for Included Voter $(\$)$ & $\$ 10$ & 13.08 & 12.90 \\
& & $(1.64)$ & $(2.20)$ \\
Share for Excluded Voter $(\$)$ & $\$ 0$ & 0.71 & 3.50 \\
& & $(2.56)$ & $(4.34)$
\end{tabular}

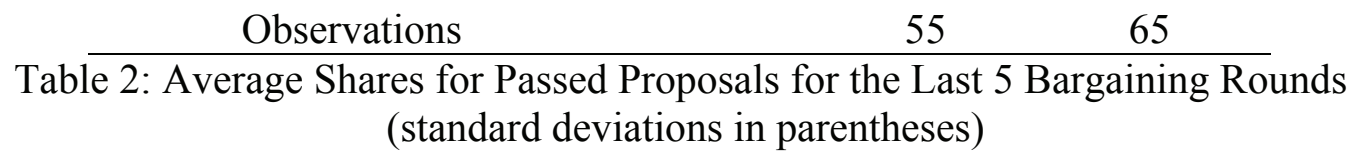

Figure 2 provides more detail regarding the proposer's payoff over the last five rounds. It highlights the increased proposer power for teams compared to individuals, as proposers more frequently keep more than $\$ 15$, along with a handful of cases where they get close to the $\$ 20$ predicted under the SSPE. In contrast, individual proposers never got to keep \$20, and there is a markedly lower frequency with which they keep more than $\$ 15$.

\footnotetext{
${ }^{22}$ There are more SSPE and Other MWC type proposals passed for teams, Mann Whitney $p=0.0373$ and $p<0.001$. The proportions of TES and Other non-MWC type proposals are also different, $p=0.012$ and $p=0.003$, while MWC Equal Split is not different, $p=0.273$. Each test uses the player average over the last five rounds, as below.

${ }^{23}$ This is determined using the average share for each player over the last five bargaining rounds. That is, there is one observation per player, and no parametric distribution assumed. All remaining statistical tests, aside from regressions, will be Mann Whitney tests.
} 


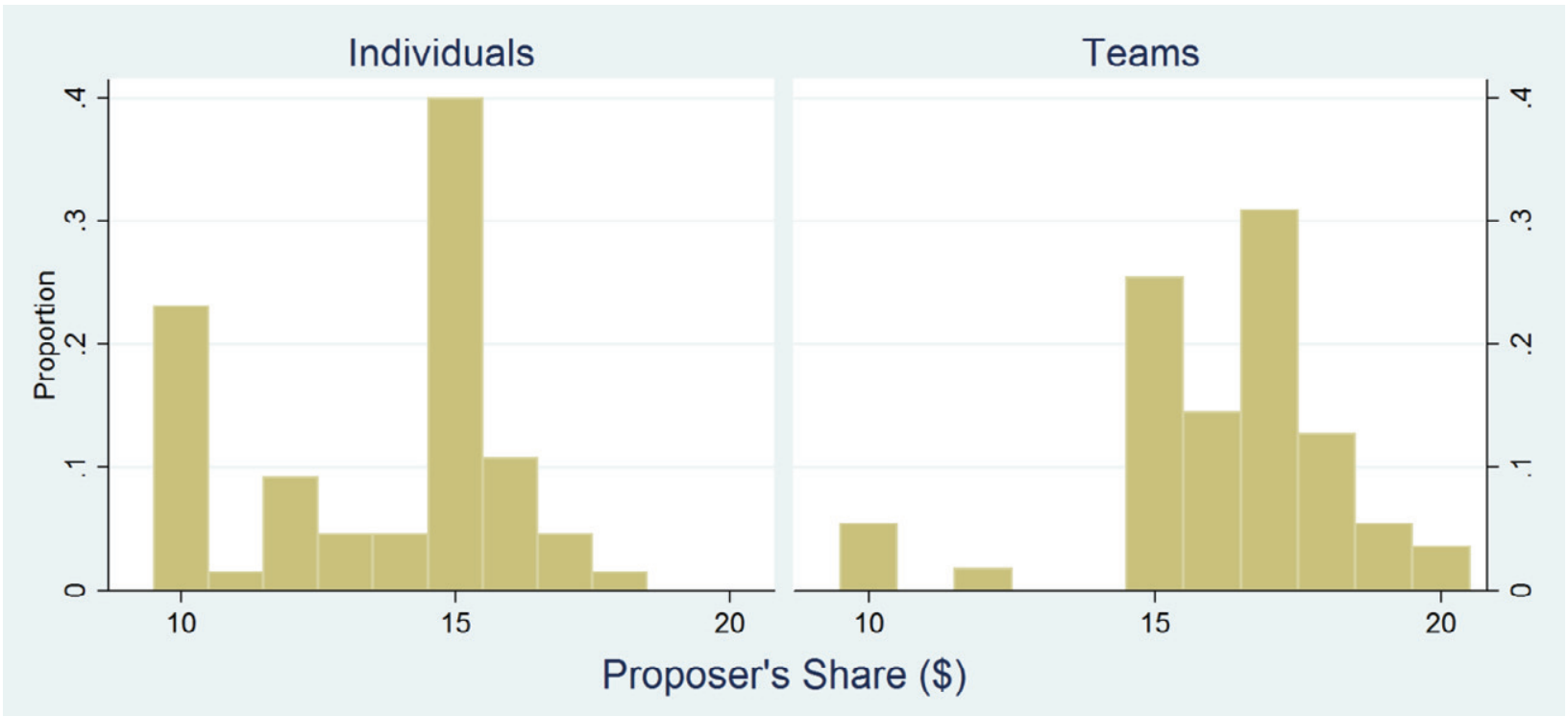

Figure 2: Histograms of Passed Proposals for the Last 5 Bargaining Rounds

The increase in proposer power under the teams treatment is partly due to increased proposer power conditional on forming an MWC: teams earn \$1.27 more than individuals conditional on forming an MWC (48.8\% of the $\$ 2.60$ overall difference reported in Table 2$){ }^{24}$ The remaining increase comes from the higher frequency of MWCs under the teams treatment (92.7\% versus $55.4 \%$ of passed proposals), as MWCs make more money available to the proposer, while keeping the included voter relatively satisfied.

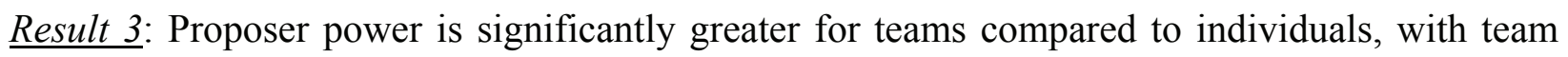
proposers earning $\$ 2.60$ more per round than individuals (19.1\% more than individuals). This increase in proposer power results equally from the increased share proposers receive within MWCs and the increased frequency of MWCs in the teams treatment.

Figure 3 provides a more complete picture of passed proposals. Proposer's share is on the $y$-axis against the included voter's share on the $\mathrm{x}$-axis. The center of each circle represents the proposal, and the size of the circle represents the relative frequency of that proposal. The downward-sloping, dashed line represents MWCs, while proposals below the line allocate some money to all three players. Not only is it more common for teams to form MWCs, but

\footnotetext{
${ }^{24}$ Proposers keep $\$ 16.66$ for teams versus $\$ 15.39$ for individuals over the over the last 5 rounds. This difference is significant at the $1 \%$ level (Mann Whitney test).
} 
individuals passed more proposals giving money to all three players even outside of a True Equal Split $(10,10,10)$.

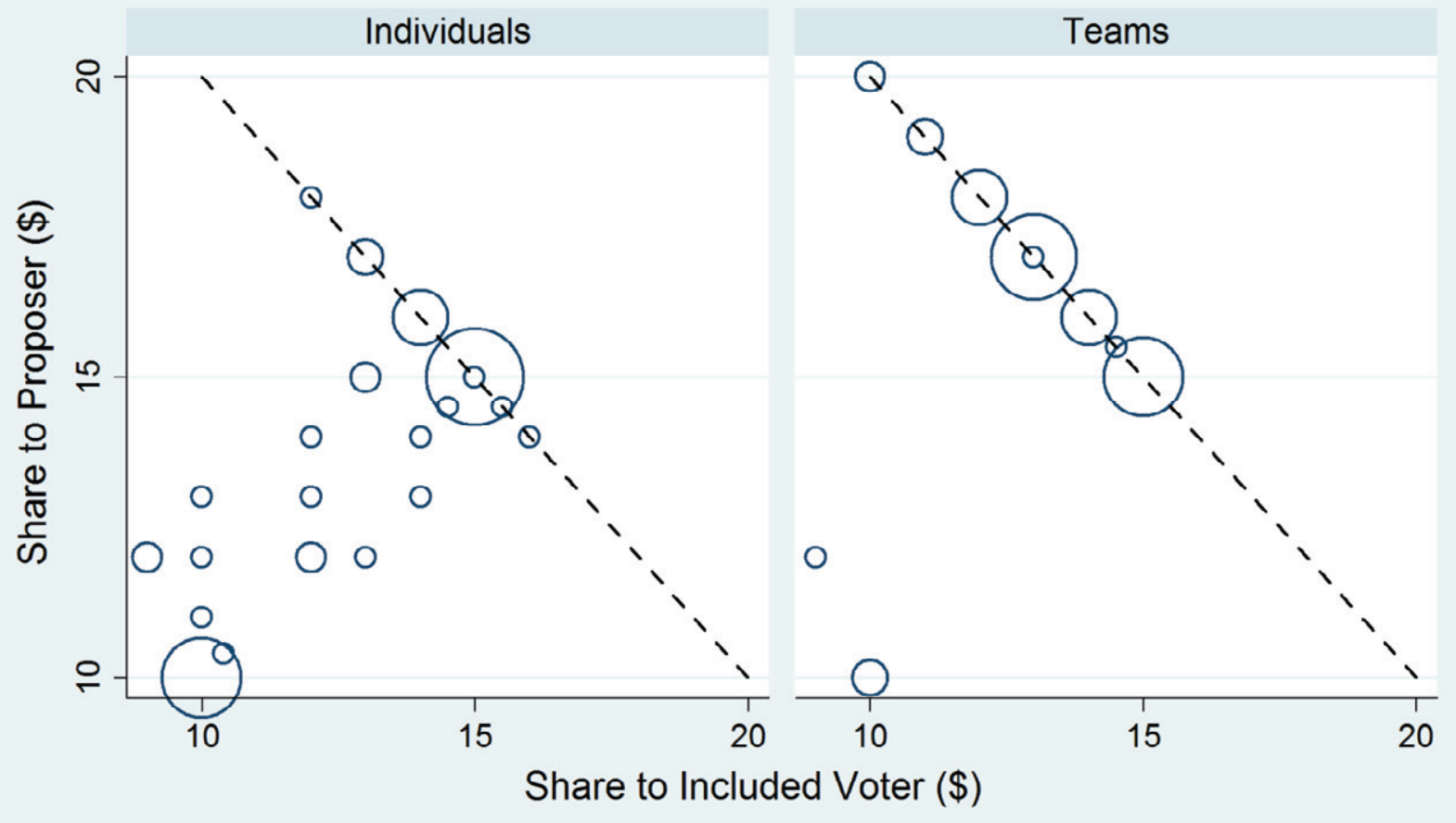

Figure 3: Proposer's and Included Voter's Shares for Passed Proposals, Last 5 Rounds

\subsection{Voting patterns}

Table 3 reports pass rates for different types of proposals over the last five bargaining rounds, along with the number of times these proposals were voted on. ${ }^{25}$ The most striking thing here is that overall pass rates and pass rates by category were essentially the same between the two treatments, with the exception of Other proposals where pass rates were substantially lower for individuals. For individuals, 12 of Other proposals consist of MWCs with an unequal split in favor of the proposer (pass rate 33.3\%), with the other 14 consisting of shares to all players (pass rate $78.6 \%$ ). In contrast for teams, Other proposals consist almost exclusively of MWCs with an unequal split in favor of the proposer. As noted earlier, teams are more likely than individuals to accept smaller shares within an MWC. This is inconsistent with the notion that they come closer to the predictions of the SSPE out of increased aggressiveness. True Equal Splits (TESs) always pass but somewhat surprisingly, they fail to get all three votes about half the time. ${ }^{26}$

\footnotetext{
${ }^{25}$ Data are for all proposals voted on for all stages in the bargaining process.

${ }^{26}$ There are very few approximate TESs that are not strict: 1 out of 4 for teams and 4 out of 18 for individuals.
} 


\begin{tabular}{|c|c|c|c|c|}
\hline \multicolumn{5}{|c|}{ Teams } \\
\hline All & SSPE & MWC Equal Split & True Equal Split & Other \\
\hline $79.7 \%$ & $45.5 \%$ & $88.0 \%$ & $100 \%$ & $(4)$ \\
$(69)$ & $(11)$ & $(25)$ & $82.8 \%$ \\
$(29)$
\end{tabular}

Table 3: Proposal Pass Rates over Last 5 Bargaining Rounds

(number of selected proposals in parentheses)

Result 4: Aggregate proposal pass rates are essentially the same for teams and individuals. This is inconsistent with the hypothesis that teams come closer to the SSPE predictions due to being inherently more aggressive.

Table 4 provides a more detailed look at voting patterns using probit regressions. The dependent variable is 1 if the vote is in favor of a proposal and 0 otherwise. Votes for excluded voters are dropped, as most of these consist of $\$ 0$ or $\$ 1$ allocations within an MWC which were rejected $100 \%$ of the time for both treatments. To include them would distort the estimates reported. Right hand side variables include a dummy (Teams) for the teams treatment (equal to 1 for teams and 0 for individuals), the share allocated to the included voter in dollars (S), the share allocated to the other (excluded) voter in dollars (SO), and terms for S and SO interacted with the Teams dummy. Errors are clustered at the player level to allow for arbitrary, withinplayer correlation. $^{27}$

Focusing on the last five bargaining rounds, the coefficient for the Teams dummy is large, positive, and statistically significant so that, other things equal, included voters were more likely to vote in favor of a proposal in the teams treatment. This in conjunction with the negative coefficient for Teams interacted with own share (Teams*S) indicates that once the included voter's share is high enough (more than \$11) teams and individuals are equally likely to vote in favor of a proposal. This is illustrated in Figure 4, which graphs the probability of a favorable

\footnotetext{
${ }^{27}$ The results are very similar when clustering at the session level.
} 
vote at various levels of own share, holding the other voter's share fixed at its average level. ${ }^{28}$ Very low included voters' shares are rejected almost all the time for both treatments. Clear differences between acceptance rates start when the included voter's share is above \$6-\$7, with no differences again at own shares of $\$ 12$ or more. ${ }^{29}$

\begin{tabular}{|c|c|c|}
\hline Vote & $\begin{array}{c}(1) \\
\text { All Rounds } \\
\end{array}$ & $\begin{array}{c}(2) \\
\text { Last } 5\end{array}$ \\
\hline Teams & $\begin{array}{l}-0.334 \\
(2.494)\end{array}$ & $\begin{array}{l}6.508 * * \\
(3.109)\end{array}$ \\
\hline $\mathrm{S}$ & $\begin{array}{l}0.362 * * \\
(0.158)\end{array}$ & $\begin{array}{l}0.751 * * * \\
(0.208)\end{array}$ \\
\hline Teams*S & $\begin{array}{c}0.072 \\
(0.179)\end{array}$ & $\begin{array}{l}-0.420^{*} \\
(0.225)\end{array}$ \\
\hline $\mathrm{SO}$ & $\begin{array}{c}0.110 \\
(0.077)\end{array}$ & $\begin{array}{l}0.339 * * * \\
(0.103)\end{array}$ \\
\hline Teams*SO & $\begin{array}{l}-0.055 \\
(0.087)\end{array}$ & $\begin{array}{l}-0.254 * * \\
(0.114)\end{array}$ \\
\hline Constant & $\begin{array}{l}-4.259 * \\
(2.262)\end{array}$ & $\begin{array}{l}-9.865 * * * \\
(2.965)\end{array}$ \\
\hline $\begin{array}{l}\text { Observations } \\
\sigma \\
\text { Log-Likelihood }\end{array}$ & $\begin{array}{l}358 \\
0.462 \\
-164.9\end{array}$ & $\begin{array}{l}170 \\
0.406 \\
-73.30\end{array}$ \\
\hline $\begin{array}{l}\text { Clustered st } \\
* * * \mathrm{p}<0 .\end{array}$ & $\begin{array}{l}\text { idard errors } \\
\text { l, } * * \mathrm{p}<0 .\end{array}$ & $\begin{array}{l}\text { parentheses } \\
* \mathrm{p}<0.10\end{array}$ \\
\hline
\end{tabular}

Table 4: Voting Probits, Included Voters Only

The positive and statistically significant value for the other (excluded) voter's share (SO) in Table 4 in conjunction with the negative coefficient for Teams interacted with the excluded voter's share (Teams*SO) indicates that individuals were more likely to vote in favor of proposals giving larger shares to the excluded voter. This suggests that individuals are more concerned with payoffs to the excluded player than teams and that greater selfishness on the part of teams contributes to meeting and beating the TW norm with respect to MWCs.

\footnotetext{
${ }^{28}$ This is the average for teams and individuals combined.

${ }^{29}$ These differences are statistically significant at the 0.05 level for each integer value in the interval $[\$ 7, \$ 11]$. Note that continuation values are the same for included voters at $\$ 10$ in both cases. Risk aversion would get players to accept offers below the $\$ 10$ continuation value, but there are very few offers in the neighborhood of $\$ 10$ and these are rejected $50 \%$ of the time.
} 


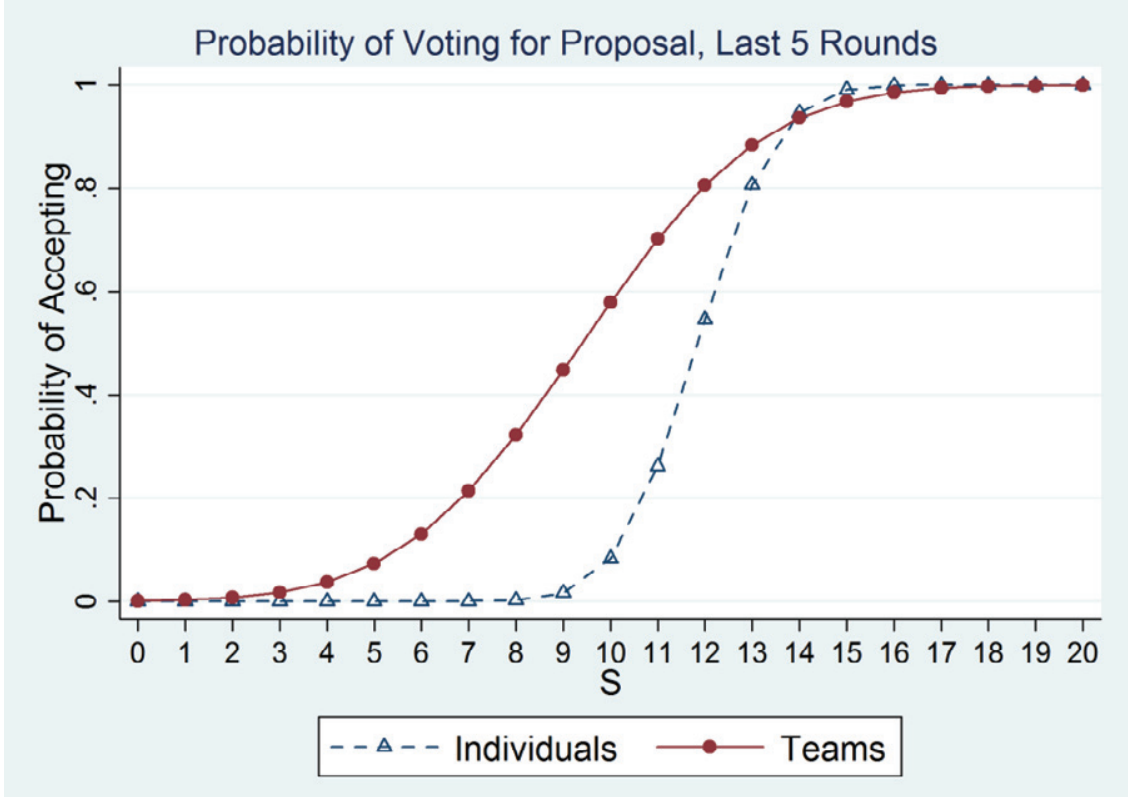

Figure 4: Predicted Voting Outcomes

However, this conclusion is premature since money for the excluded voter is inversely related to the difference in shares between the proposer and the included voter. ${ }^{30}$ As such an alternative explanation for the greater selfishness on the part of teams suggested in Table 4 is that individual voters are more sensitive to differences between their own payoff and the proposer's. This results from the fact that, since all three shares add up to $\$ 30$ and we include a constant and own share in the regression, including the excluded voter's share is econometrically equivalent to including the proposer's share (or the difference between the proposer's share and own share). As such, the results in Table 4 are also consistent with the idea that teams are not as sensitive to differences between their share and the proposer's share, conditional on receiving a sufficiently large share.

There are two sources of support for this interpretation, both of which show that individuals have essentially no concern for the impact of their actions on third parties when it conflicts with own payoffs, which leaves no room for teams to be even more selfish. One comes from a closely related three player ultimatum game experiment (with individuals) in which a proposer splits a sum of money between herself and two potential responders (Kagel and Wolfe, 2001). After the proposer makes her allocation, one of two potential responders is randomly chosen to accept or reject the proposal. In one treatment, as with the usual ultimatum game, if

\footnotetext{
${ }^{30}$ These correlation coefficients are -0.58 and -0.80 for teams and individuals, respectively.
} 
the proposal is rejected, all three players get $\$ 0$; otherwise, the proposal is binding. In a second treatment, if the proposal is rejected, both the responder and the proposer get $\$ 0$, but the third player loses $\$ 10^{31}$ Both with and without the penalty for third players, low offers are met with rejection at essentially the same rate, indicating little if any regard for the impact on the third player. Second, Baranski and Kagel (2015), in their experiment on the impact of cheap talk in the BF game, show that the predominant mode of bargaining was for potential coalition partners to make offers regarding the shares they were willing to accept: in the last five bargaining rounds well over $90 \%$ of voters called for giving the third player nothing so that the proposer and voter in question would have more money to split.

For teams to be more selfish than this would require an active interest in punishing third parties. However, based on the results reported in Halevy, Bornstein, and Sagiv (2008), this is extremely unlikely. In that experiment individuals can make costly contributions to either of two pools, one that benefits the in-group but harms the out-group and one that benefits the in-group with no impact on the out-group. Results show that contributions are directed almost exclusively to the alternative that does not harm the out-group. However, when faced with only the pool that harms the out-group, individuals contribute, harming the out-group to maximize own earnings.

Result 5: Probits investigating voting patterns show that shares to the included voter in the interval [\$7, \$11] are significantly more likely to be rejected for individuals than for teams, with offers below $\$ 7$ (above $\$ 11$ ) equally likely to be rejected (accepted). Results from related experiments sort out between competing explanations for these higher rejections rates, favoring the hypothesis that it is increased sensitivity on the part of individuals to differences between own payoff and the proposer's payoff that underlie the higher rejection rates, as opposed to teams being more selfish or less concerned with payoffs to the excluded voter. This again provides evidence in favor of teams coming closer to equilibrium outcomes due to greater insightfulness as opposed to greater selfishness.

\section{Team Dialogues}

Team dialogues were analyzed for further insight into the behavioral processes underlying team choices. We (the experimenters) first looked at the team chats to identify relevant categories for

\footnotetext{
${ }^{31}$ This was subtracted from a players starting capital balance. The instructions were purposely couched in terms of the third player losing $\$ 10$ in an effort to make the negative impact of rejection more salient.
} 
better understanding behavior. We then had two undergraduates independently code the data for one session and met with the coders to resolve major discrepancies in their understanding of coding categories. After that, the two independently coded up the dialogues from the other two sessions. The focus in the coding was to determine when teams recognized that they only needed one vote to get their proposal approved, leading to little or no money for one of the two voters in order to get a larger own share. Table 5 reports the coding categories, the frequency with which each category was coded by at least one of the coders, and the agreement rate between the two coders (reported in parentheses).

\begin{tabular}{|c|l|c|}
\hline $\begin{array}{c}\text { Coding } \\
\text { Category }\end{array}$ & \multicolumn{1}{|c|}{\begin{tabular}{c}
\multicolumn{1}{|c|}{ Description of Coding Category } \\
\hline 1
\end{tabular}} & $\begin{array}{c}\text { Percentage } \\
\text { of Teams }\end{array}$ \\
\hline & $\begin{array}{l}\text { Team recognizes in either the dry run or Round 1 of actual play that } \\
\text { they only need one other team to vote for their proposal and make } \\
\text { very uneven proposals designed to capture one of the two votes. }\end{array}$ & $\begin{array}{c}15.2 \% \\
(20.0 \%)\end{array}$ \\
\hline 2 & $\begin{array}{l}\text { Same as category 1 but explicitly discussing an MWC, i.e., giving the } \\
\text { excluded voter \$1 or less. }\end{array}$ & $\begin{array}{c}75.8 \% \\
(80.0 \%)\end{array}$ \\
\hline 3 & $\begin{array}{l}\text { Same as categories 1 or 2 above but don't want to make payoffs too } \\
\text { uneven until later rounds out of concern for group dynamic. }\end{array}$ & $\begin{array}{c}6.1 \% \\
(100.0 \%)\end{array}$ \\
\hline 4 & $\begin{array}{l}\text { Team reaches agreement on category 1 or 2 after Round } 1 . \\
30.3 \% \\
(80.0 \%)\end{array}$ \\
\hline 5 & $\begin{array}{l}\text { Team discusses giving money to all teams. } \\
18.2 \% \\
(16.7 \%)\end{array}$ \\
\hline 6 & $\begin{array}{l}\text { Teams have other regarding preferences that call for giving roughly } \\
\text { equal shares to all, but they drop the equal shares on account of others } \\
\text { choosing 1 or 2. }\end{array}$ & $\begin{array}{c}9.1 \% \\
(0.0 \%)\end{array}$ \\
\hline 7 & $\begin{array}{l}\text { Breakdown of the stationarity assumption on the part of voters, } \\
\text { planning to punish this stage's proposer should they become the } \\
\text { proposer in the next stage. }\end{array}$ & $\begin{array}{c}21.2 \% \\
(42.9 \%)\end{array}$ \\
\hline 8 & $\begin{array}{l}\text { Breakdowns of the stationarity assumption on the part of proposers, } \\
\text { planning to punish one of this stage's voters who rejected their offer in } \\
\text { the next stage. }\end{array}$ & $\begin{array}{c}27.3 \% \\
(11.1 \%)\end{array}$ \\
\hline
\end{tabular}

Table 5: Coding Categories for Teams

(agreement rate in parentheses)

The most commonly coded category is 2 - recognizing in the dry run, or in Round 1 , that as proposers they only needed one other team to vote for their proposal. A dialogue of this sort follows (from the dry run; ID numbers precede each comment): 
32: same here

31: We only need the vote of one other team

32: you want to play this to win or to be nice to everyone

31: WIN

32: ok same

32: lets not give it away in the trial run now though

32: lets do 101010

32: for the trial

31: sounds good

32: what was your strategy?

31: do something like 17 us, 13 another, then just give 0 to the last

32: i agree we can try the 17-13 early and see how it goes

The frequency with which 2 was coded is a bit above the actual frequency of MWCs in Round 1 on account of considerations expressed in category 3, as well as coding errors reflected in disagreements between the two coders. ${ }^{32}$ To be more precise, $81.5 \%$ of the teams coded under categories 1 or 2 proposed an MWC in the first bargaining round, versus $16.7 \%$ of the teams not coded in either category, providing strong evidence that team discussions relate directly to behavior.

Other coding categories of particular interest are 5 and 6 which reflect a taste for roughly equal, or at least respectable, shares all around. There is little evidence for teams having tastes of this sort, as only 3 out of 33 teams were coded under category $6 .^{33}$ And no teams were identified that maintained their concern for respectable shares all around through the end of the session. Rather, most of the teams roughly follow standard theory and propose MWCs, either on their own or after reflecting on other teams proposing MWCs.

Also of interest are categories 7 and 8, which call into question the stationarity assumption underlying the SSPE. Although these are not coded that frequently (on account of the high frequency of Stage 1 proposals being accepted) and the coders disagree on this score,

\footnotetext{
${ }^{32}$ We tried combining closely related categories to increase agreement rates - in particular categories 1 and 2, and 7 and 8 , but this had minimal impact.

${ }^{33}$ To take one case: in Round 1 one of these teams proposed a True Equal Split which passes. In Round 2 they propose $(15,7.5,7.5$; with their payoff listed first) which is rejected, only to have an MWC Equal Split (where they got $\$ 0$ ) passing. In Round 3 they vote in favor of an MWC Equal Split where they got $\$ 15$ (their proposal was for a 12, 12, 6 split). In Round 4, they propose an MWC Equal Split noting "they're gonna continue doing the 15150 , so we might as well do the same" and continue doing so (with one exception) for the remainder of the session.
} 
there is clear evidence for teams retaliating more against proposers whose proposals were rejected: $80.0 \%$ of the time when an MWC was rejected in Stage 1, that team was given $\$ 1$ or less by the new proposer in Stage 2 versus 34.6\% for individuals. ${ }^{34}$ More generally, the empirical continuation value for proposals that failed is $\$ 8.54$ for individuals versus $\$ 2.40$ for teams, with the difference between the two significant at the $5 \%$ level or better with clustering at either the player or the session level. In contrast, the difference between the $\$ 8.54$ for individuals and the continuation value without punishment $(\$ 10)$ is not significant at conventional levels. The greater propensity for teams to punish players whose proposals were voted down in the previous stage has several implications. First, it is inconsistent with the stationarity assumption, which rules out retaliation of this sort. Second, it constrains teams from proposing MWCs with too large a share for the proposer, since if the proposal fails, the proposer is likely to get a very small share when new proposals are called for. Finally, this difference in retaliatory behavior is consistent with teams being more aggressive than individuals. While teams are more aggressive here, the increased aggression has no direct impact on team earnings and may indirectly moderate proposer power. However with respect to voting, there is conflict between aggression and maximizing expected earnings, with the "rational," income maximizing effect winning out. ${ }^{35}$

Result 6: Team dialogues show that by Round 1, over $81.8 \%$ of teams were coded as recognizing they only needed one other team to vote for their proposal, with $81.5 \%$ of these teams proposing an MWC in Round 1. There is little evidence that teams are concerned with equitable payoffs for all three players, and what concerns there are either were not acted on or did not persist. There is also clear evidence of history dependent behavior following rejection of a proposal for teams, with teams retaliating against the previous proposer. ${ }^{36}$ Although teams are more aggressive on this dimension, it contrasts with teams being less aggressive with respect to voting.

\footnotetext{
${ }^{34} \mathrm{~A}$ probit testing if this difference is significant can reject the null hypothesis at the $1 \%$ level for clustering at the player level and at $10 \%$ for clustering at the session level.

${ }^{35}$ In this respect, it is interesting to note that teams' greater willingness to accept low offers stops for shares below $\$ 7$, compared to the ex ante continuation value of $\$ 10$, consistent with risk aversion on voters' part (Harrington, 1990). Although we do not place too much stock in risk aversion underlying this willingness to accept less than the risk neutral continuation value of the game, the broader point is that greater aggressiveness can be kept in check when it conflicts with maximizing earnings, at least in bargaining contexts (also see Borenstein and Yaniv, 1998).

${ }^{36}$ This retaliation has the same effect as the gambler's fallacy specified in Nunnari and Zapal (2014). Note, however, that in reading the team dialogues we do not find explicit statements in which teams' decisions to accept or reject a proposed allocation is based on their specification of the gambler's fallacy.
} 
The difference is that in retaliating against proposers, there is no conflict between aggression and the "rational," income maximizing choice. In contrast, with respect to voting, these two behavioral forces conflict, with the "rational," income maximizing choice winning out.

\section{Summary and Conclusions}

Results are reported for teams versus individuals in the Baron-Ferejohn (BF, 1989) legislative bargaining game. There were several reasons underlying the motivation for this experiment: first, many economic decisions are made by teams as opposed to individuals, which is even more likely to be true in multilateral bargaining settings, so it is important to understand what, if any, differences in behavior there are between the two cases; e.g., do teams come closer to the stationary subgame perfect equilibrium (SSPE) prediction than individuals? Second, the BF game is well suited to sorting out between different explanations for why teams tend to come closer to equilibrium predictions than individuals among three possible driving forces: (i) teams, having two heads to work with, may be more insightful and have a better understanding of the underlying strategic tradeoffs, (ii) teams are inherently more aggressive, and/or (iii) teams are more selfish with less regard for others, particularly when monetary payoffs are at stake.

Our results show that teams come closer to the stationary subgame perfect equilibrium predictions than individuals as they have a significantly higher frequency of minimum winning coalitions (MWCs), which in turn results in increased proposer power. We rule out increased aggressiveness as driving these results, as stage one proposals pass at the same rate for teams and individuals, with teams as, or more, willing to accept smaller shares than individuals. We rule out increased selfishness as driving these results on the basis of a closely related three player ultimatum game experiment (Kagel and Wolfe, 2001) and results for the BF game reported in Baranski and Kagel (2015), both of which show little room for teams to be more selfish than individuals with respect to third parties. The fact that teams meet and beat the demanding truth wins (TW) norm with respect to the frequency of MWCs provides strong positive evidence in favor of the teams' greater insightfulness. The TW norm applies to eureka type insights, which

once obtained are reasonably obvious and readily explained to others. They are generally considered to be indicative of team synergies in the deliberative process (Lorge and Solomon, 1955, and Davis, 1992), with most settings of interest to economists too complicated for TW to reasonably apply. At the same time, teams are more aggressive than individuals in punishing previous proposers whose proposals were rejected. Interestingly, this type of aggressiveness 
should, if anything, work against the extreme proposer power that the theory predicts but is far from strong enough to eliminate the large increase in proposer power reported for teams.

\section{Acknowledgements}

This research was partially supported by NSF grant SES-1226460. We have benefited from comments of two anonymous referees and an editor, as well as participants at seminars at The Ohio State University and the ESA North American meetings in Santa Cruz. The usual caveat applies. 


\section{References}

Agranov, Marina, and Chloe Tergiman. 2014. "Communication in multilateral bargaining". Journal of Public Economics. 118 (1): 75-85. 10.1016/j.jpubeco.2014.06.006

Baron, David P., and John A. Ferejohn. 1989. "Bargaining in Legislatures". The American Political Science Review. 83 (4): 1181-1206. 10.2307/1961664

Bazerman, M. H., and W. F. Samuelson. 1983. "I Won the Auction But Don't Want the Prize". Journal of Conflict Resolution. 27 (4): 618-634. 10.1177/0022002783027004003

Baranski, Andrzej and John H. Kagel. 2015. "Communication in Legislative Bargaining" Journal of the Economic Science Association. (in press). 10.1007/s40881-015-0011-5

Bornstein, Gary, and Ilan Yaniv. 1998. "Individual and group behavior in the ultimatum game: Are groups more "rational" players?" Experimental Economics. 1 (1): 101-108. 10.1007/BF01426217

Casari, Marco, Christine Jackson, and Jingjing Zhang. 2012. "When Do Groups Perform Better than Individuals? An Acquiring a Company Experiment." IEW - Working Papers.

Charness, Gary, and Matthias Sutter. 2012. "Groups make better self-interested decisions". Journal of Economic Perspectives. 26 (3): 157-176. 10.1257/jep.26.3.157

Davis, James H. 1992. "Some compelling intuitions about group consensus decisions, theoretical and empirical research, and interpersonal aggregation phenomena: selected examples, 1950-1990." Organizational Behavior \& Human Decision Processes. 52 (1).

Fischbacher, Urs. 2007. "z-Tree: Zurich Toolbox for Ready-made Economic Experiments." Experimental Economics. 10 (2): 171-178. 10.1007/s10683-006-9159-4

Fréchette, Guillaume, John H. Kagel, and Massimo Morelli. 2005. "Nominal Bargaining Power, Selection Protocol, and Discounting in Legislative Bargaining." Journal of Public Economics. 89 (8): 1497-1517. 10.1016/j.jpubeco.2004.02.009

Frechette, Guillaume. 2009. "Learning in a multilateral bargaining experiment". Journal of Econometrics. 153 (2): 183-195. 10.1016/j.jeconom.2009.06.004

Halevy, Nir, Gary Bornstein, and Lilach Sagiv. 2008. "'In-group love' and 'out-group hate' as motives for individual participation in intergroup conflict: a new game paradigm". Psychological Science. 19 (4): 405-11. 10.1111/j.1467-9280.2008.02100.x

Herings, P. Jean-Jacques, Andrey Meshalkin, and Arkadi Predtetchinski. 2013. Subgame perfect equilibria in majoritarian bargaining. GSBE Research Memorandum. 
Harrington, Joseph E. 1990. "The role of risk preferences in bargaining when acceptance of a proposal requires less than unanimous approval". Journal of Risk and Uncertainty. 3 (2): 135-154. 10.1007/BF00056369

Insko, Chester A. and John Schopler. 1987. Categorization, competition, and collectivity. Group processes, vol. 8, edited by C. Hendrick, 213-51. Newbury Park, CA: Sage.

Kagel, John H. and Peter McGee. 2015. "Team versus individual play in finitely repeated prisoner dilemma games". Unpublished manuscript.

Kagel, John H., and Katherine Willey Wolfe. 2001. "Tests of Fairness Models Based on Equity Considerations in a Three-Person Ultimatum Game". Experimental Economics. 4 (3): 203-219. 10.1023/A:1013290819565

Kugler T., Kausel E.E., and Kocher M.G. 2012. "Are groups more rational than individuals? A review of interactive decision making in groups." Wiley Interdisciplinary Reviews: Cognitive Science. 3 (4): 471-482. 10.1002/wcs.1184

Lorge, Irving, and Herbert Solomon. 1955. "Two models of group behavior in the solution of eureka-type problems". Psychometrika. 20 (2): 139-148. 10.1007/BF02288986

Nunnari, S. and Zapal, J. (2014) “Gambler's fallacy and imperfect best response in legislative bargaining" unpublished manuscript.

Palfrey, Thomas. 2015. "Experiments in Political Economy." To appear in The Handbook of Experimental Economics, Vol 2. John H. Kagel and Alvin E Roth (eds). Princeton University Press.

Schopler, John, and Chester A. Insko. 1992. "The Discontinuity Effect in Interpersonal and Intergroup Relations: Generality and Mediation". European Review of Social Psychology. 3 (1): 121-151. 10.1080/14792779243000041 